\title{
Os verbos ter e haver existenciais no português falado em Luanda-Angola ${ }^{1}$
}

\section{The existential verbs ter and haver in the Portuguese spoken in Luanda-Angola}

Silvana Silva de Farias Araujo², Nathalia dos Santos Dantas ${ }^{3}$

As autoras agradecem aos colegas do GT de Sociolinguística da Associação Nacional de PósGraduação e Pesquisa em Letras e Linguística (ANPOLL), pelas sugestōes feitas, ao ter sido apresentado este artigo no XXXI Encontro Naciona da ANPOLL, ocorrido na UNICAMP. Agradecem ambeem aos Pareceristas ad hoc, pelas sugestoes poviadas pelo editor deste perí́dico. Obviamente possíveis falhas remanescentes são de nossa esponsabilidade.

Professora Adjunta da Universidade Estadual de Feira de Santana (UEFS), onde coordena Programa de Pos-Graduaçáo em Estudos voltadas para a formac̃ã do português brasileiro, com estudos sobre contatos linguísticos variedades africanas do português e variedades linguísticas do semiárido baiano (comunidades urais, urbanas e rurbanas.

E-mail: silvana.uefs.2014@gmail.con

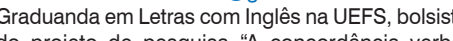
m Luanda-Angola: elementos para a discussão sobre a formação do português brasileiro", pelo Programa de Bolsas de Iniciação Científica (CNPq). E-mail: nathi.ndantas@gmail.com
RESUMO: Com o arcabouço teórico-metodológico da Sociolinguística Variacionista, pesquisa-se a variação no uso dos verbos ter e haver em construções existenciais, com dados orais do português de Luanda (PL). Objetiva-se contribuir para o entendimento acerca da natureza do português de variedades africanas. Os resultados mostram que há uma variação estruturada no PL, sendo que o ter existencial é amplamente utilizado, com uma frequência de $42 \%$ e é favorecido, principalmente, pelo fator baixa ou nenhuma escolarização; embora, no cômputo geral dos dados, o verbo haver predomine em construções existenciais, com uma frequência de $58 \%$. Os resultados são analisados qualitativa e quantitativamente em tempo aparente. Os dados foram levantados na fala de 23 informantes, em entrevistas sociolinguísticas pertencentes ao acervo dos projetos "Em busca das raízes do português brasileiro" e "A concordância verbal em Luanda-Angola: elementos para a discussão sobre a formação do português brasileiro", sediados na Universidade Estadual de Feira de Santana. Nesse sentido, buscando contribuir para os estudos sobre a formação da realidade sociolinguística brasileira, acredita-se que é importante a realização de estudos que se centrem em dados coletados em outros continentes que não apenas o europeu - como propôs Petter (2007) -, pois, assim, torna-se possível a comparação entre a variedade brasileira e as variedades africanas do português, ampliando-se o debate sobre a influência do contato linguístico na formação dessas variedades e a discussão sobre a atuação de fatores inguísticos e socioculturais em fenômenos linguísticos variáveis.

Palavras-chave: Verbos ter e haver; Português luandense; Verbos existenciais.

ABSTRACT: Within the theoretical and methodological framework of the Variationist Sociolinguistics, it researches the variation into the use of the verbs to have (ter/haver) in existential constructions, with oral data from the Portuguese spoken in Luanda (PL). It aims to contribute to the comprehension about the nature of the African Portuguese varieties. The results show that there is a structured variation in the PL, being the existential form of the verb "ter" widely used, with a frequency of $42 \%$ and it is increased by the low schooling factor; although, in general terms, the verb "haver" prevails in the existential structures, with a frequency of 58\%. The results are analyzed qualitatively and quantitatively in apparent time. The data were collected in the speech of 23 informants in sociolinguistic interviews belonging to the collection of the project "In search of the roots of Brazilian Portuguese" and "A verbal agreement in Luanda Angola: elements for discussion on the formation of Brazilian Portuguese", both based at State University of Feira de Santana. In this sense, seeking to contribute to the studies on the formation of Brazilian sociolinguistic reality, it is believed that it is important to conduct studies that focus on data collected in other continents that not only European - as proposed Petter (2007) - because, thus, it becomes possible to compare the Brazilian and African varieties of Portuguese, expanding the debate on the influence of language contact in the formation of these varieties and expand the discussion of the role of linguistic and sociocultural factors in linguistic phenomena variables.

KEYwORDS: Verbs ter and haver; Portugueses of Luanda; Existencial Verbs. 


\section{Introdução}

$\mathrm{N}$ este estudo, aborda-se a variação entre os verbos ter e haver em construções existenciais prototípicas na fala luandense (popular e culta), com base nos pressupostos da Sociolinguística Variacionista laboviana (LABOV, 1994). Antes, contudo, de examinar a variação com os verbos existenciais, faz-se uma descrição qualitativa e quantitativa acerca de outros contextos de uso dos verbos ter e haver levantados no corpus sob análise, a saber: de posse, de tempos compostos, de verbos modais, de verbos funcionais e de indicação de tempo decorrido, cujos resultados estão apresentados na Tabela $\mathbf{1}$, adiante apresentada.

A temática da variação ter e haver, tanto em construções existenciais quantos nas demais funções mencionadas anteriormente, já vem sendo analisada há bastante tempo com dados do português brasileiro (PB) e do europeu (PE), conforme atestam os trabalhos citados neste texto. No que concerne ao português falado em outras variedades transcontinentais, a exemplo das variedades africanas, percebe-se que ainda há uma carência de pesquisas. Nesse sentido, este estudo contribui para sanar essa lacuna, trazendo à tela o português falado em Luanda, capital e maior cidade de Angola, a qual também é capital da província de Luanda. O objetivo geral desta pesquisa foi investigar possíveis semelhanças a respeito do uso dos verbos ter e haver, comparando os resultados alcançados com os obtidos por pesquisadores que analisaram a variação no PB e no PE. Partiu-se do princípio de que esse aumento do campo de observação pode proporcionar um melhor entendimento acerca da importância do contato do português com línguas africanas do grupo banto e, também, uma avaliação da atuação de fatores internos e externos na estruturação desse fenômeno variável, observando se é similar ao que se verifica em outras variedades da língua portuguesa.
Considerando, pois, o marcante contato da população de origem africana com a língua portuguesa na história sociolinguística do Brasil, os estudos sobre a realidade linguística de países africanos devem se multiplicar como um meio para recolher evidências que ampliem a compreensão sobre a formação histórica do português brasileiro, bem como para a compreensão acerca da influência de fatores linguísticos e socioculturais nos usos linguísticos.

A partir desta introdução, o artigo está estruturado da seguinte forma: na seção 1 , faz-se um breve resgate histórico acerca do uso dos verbos ter e haver, evidenciando como este último passou de possessivo para existencial na história da língua portuguesa. Em seguida, na seção 2, apresenta-se uma revisão da literatura com ênfase na comparação entre o PB e o PE, no que tange ao uso dos verbos ter e haver existenciais. Após essas discussões, passa-se, na seção 3, a uma exposição sobre aspectos metodológicos e a comunidade de fala e apresenta-se a análise variacionista dos resultados alcançados, fazendo-se uma discussão sobre as construções com esses verbos em diferentes contextos linguísticos no falar luandense e, depois, detendo-se no uso variável dos verbos ter e haver em construções existenciais. Por fim, são apresentadas as principais conclusões.

\section{Breve resgate histórico de ter e haver na evolução da língua portuguesa}

No português brasileiro corrente, as construções existenciais podem ser construídas com os verbos ter e haver, conforme é exemplificado nas frases seguintes:

(1) Tem uma partezinha assim pra você botar os pés. (CALLOU; AVELLAR, 2000, p. 87) 
(2) Há essa preocupação. (CALLOU; BATISTA; ALMEIDA, 2015, p. 191)

(3) Na televisão tem poucos musicais [...] (BATISTA, 2012, p. 52)

(4) E os cachorros que sempre... sempre... haviam muitos lá, bassês, conhece? (CALLOU; BATISTA; ALMEIDA, 2015, p. 191)

(5) tinha o Senac que atendia pra almoço. (MARTINS; CALLOU, 2003, p. 01)

(6) houve uns dois crimes aí que chocaram um pouco. (VITÓRIO, 2013, p. 80)

Embora não seja o cerne deste trabalho, cabe notar que, quando o sintagma nominal (SN)-argumento interno é de número plural, as formas verbais existenciais podem sofrer flexão de número, como se verifica nos exemplos (8):

(7) tem umas partes assim agressivas. (VITÓRIO, 2011, p. $79^{1}$

(8) tinham duas concorrências. (CALLOU; BATISTA; ALMEIDA, 2015, p. 191)²

Segundo Callou, Batista e Almeida (2015, p. 192), no PB do século XXI, essa flexão plural, embora não seja muito frequente, é motivada quando o falante se encontra numa situação formal, fazendo uso de gêneros textuais mais monitorados, a exemplo de discursos políticos; em situações, portanto, que podem ser consideradas de hipercorreção. As explicações para essa possível flexão podem ser várias, desde as estruturais (como, por exemplo, o fato de o falante interpretar como sujeito o sintagma nominal que se segue ao verbo existencial em estruturas impessoais) às explicações históricas. Nesta seção, o foco estará nas históricas.

\footnotetext{
Segundo Callou, Batista e Almeida (2015, p. 192), "essa possibilidade de pluralização é inibida quando o verbo está no presente do indicativo [...]". Atente-se ainda à impossibilidade de diferenciação tem/têm na modalidade oral do PB.

2 É sabido que é muito criticada em gramáticas prescritivas a flexão de plural com o verbo haver existencial, em, por exemplo, sentenças como "Houveram problemas" e "haviam candidatos" (exemplos meramente ilustrativos, isto é, não foram retirados de nenhum banco de dados).
}

Inicialmente, é preciso mencionar que o verbo haver é derivado do verbo latino clássico habere, enquanto o verbo ter, do verbo tenere. Nesse sentido, Costa (2010, p. 61), destaca as relações de proximidade entre esses verbos latinos:

0 verbo habere comportava, entre outros, os seguintes significados: ter, possuir, guardar, dever; por outro lado, tenere significava segurar, obter, ser senhor de, ocupar, guardar, entre outros. Podemos comprovar que havia já alguns pontos comuns entre a significação dos dois verbos, pois ambos "foram usados para indicar a posse de coisas materiais e também para relacionar o sujeito a seu complemento, o que deve ser considerado uma posse espiritual" (SAMPAIO, 1978, p. 1).

$\mathrm{Na}$ fase arcaica da língua portuguesa ${ }^{3}$, as estruturas mais frequentes em que se utilizavam esses verbos continuam sendo as estruturas de posse. Assim, embora inicialmente fossem comuns frases como “...outra moller que aia marido..." ${ }^{4}$, com o passar do tempo, habere foi sendo preterido pelo verbo tenere, ganhando espaço e maior aceitação entre os falantes, conforme explana Costa (2010, p. 64):

"Aver", que no início do século XIII se apresentava como o verbo principal para a expressão de posse em português, foi gradualmente cedendo o seu lugar a "teer", em todas as possibilidades de utilização de atributos possessivos.

Segundo Mattos e Silva e Machado Filho (2009, p. 338), ter passa a predominar como possessivo já no século XVI. Essa progressiva substituição resultou, nos dias atuais, na clara preferência pela utilização do verbo ter como valor de posse, não existindo mais o verbo haver com esse valor

3 Século XIII a $1 \stackrel{\text { a }}{ }$ metade do séc. XVI. Foi utilizada a classificação adotada por Mattos e Silva e Machado Filho (2009).

extrato de Callou e Avelar (2012, p. 229), que levantou o dado do Corpus Informatizado do Português Medieval - CIPM (Tycho). 
semântico. Ainda segundo os autores supracitados, é também no século XVI, que o verbo ter emerge como existencial, sendo documentado, inclusive, na Gramática pedagógica de João de Barros, passando a variar com o haver existencial, que a esta altura já havia tomado para si o valor de existência, antes do domínio do verbo ser.

Em relação à possibilidade de concordância com o SN plural aludida acima, Callou, Batista e Almeida (2015) atribuem essa possibilidade ao fato de as construções existenciais com ter e haver terem herdado aspectos sintático-semânticos de suas versões possessivas, entre elas, a possibilidade de concordância, "comprovando que um item pode emergir em um novo contexto sem perder características de suas versões anteriores" (CALLOU; BATISTA; ALMEIDA, 2015, p. 192). A propósito, Callou (2008) assinala que, em textos escritos nas décadas de quarenta e de cinquenta do século XVI, encontram-se evidências, embora raras, tanto de ter "existencial" quanto de haver existencial com concordância, "lembrado por Ivo Castro, e anotado como 'novidade' no século XVIII por Said Ali” (CALLOU, 2008, p. 61).

Em resumo, observa-se que o verbo ter foi ganhando, cada vez mais, espaço na história da língua portuguesa, de maneira que excluiu totalmente o uso de haver com valor de posse e ainda passou a disputar com este verbo o sentido existencial. No português brasileiro, isso é bem notável, sendo agramaticais sentenças como (09) e (10) e gramaticais/aceitáveis sentenças como (11).

(9) *O menino houve problemas para chegar no horário.

(10) *Ele há carro

(11) Não há/tem cadeiras na sala.

Nesse sentido, cabe analisar, contrastivamente, como se processa, atualmente, no português brasileiro e no português europeu essa evolução histórica, que, conforme se explanou acima, vem ocorrendo desde o latim. Desse modo, na seção 2, é feito um cotejo entre as duas variedades nacionais/continentais do português, a brasileira e a europeia.

\section{Ter e haver como verbos existenciais no português brasileiro e no português europeu}

Os estudos centrados no uso variável dos verbos ter e haver com sentido de existência demonstram que, no PB, construções existenciais são normalmente formadas com o verbo ter, estando o processo de substituição de haver por ter em estágio avançado, principalmente em contextos menos formais de produção e na modalidade oral da língua.

Callou (2012), ao investigar a fala culta ${ }^{5}$ concernente a duas cidades brasileiras, Salvador (região Nordeste) e Rio de Janeiro (região Sudeste), em tempo real de curta duração (décadas de 70 e de 90, do século XX), concluiu que há uma acentuada preferência pelo ter-existencial, sendo possível, inclusive, identificar uma mudança em progresso: "o percentual de ter salta de $63 \%$, em 70 , para $76 \%$, em 90 , no Rio de Janeiro, e, na fala culta de Salvador, o percentual passa de $74 \%$, em 70 , para $86 \%$, em 90." (CALLOU, 2012 , p. 162). A autora ainda comparou os resultados da fala culta brasileira com dados do português europeu (PE) falado culto ${ }^{6}$, também com corpora referentes às duas décadas, e identificou que, no PE, construções existenciais são expressas predominantemente, nas duas sincronias, com a forma padrão haver, em oposição ao $\mathrm{PB}$, o qual dá preferência ao ter-existencial, embora não seja uma mudança concluída e ainda mantenha o seu valor de posse

\footnotetext{
5 Amostras do Projeto NURC

6 Amostras do Projeto VARPORT.
} 
concomitantemente ao de existência. Ressalta-se que também na fala não culta $^{7} \mathrm{o}$ uso de ter existencial é predominante no $\mathrm{PB}$, como constatou Duarte (2003), também realizando um estudo em tempo real de curta duração. Na amostra da fala carioca do ano de 1980, o percentual de ter encontrado foi de $87 \%$, ao passo que o de haver foi de $10 \%$. Na amostra do ano de 2000, esse percentual muda para 91\% contra $6 \%$ de uso de haver. ${ }^{8}$

Há, nitidamente, um uso diferenciado em relação aos verbos ter e haver existenciais no PB e no PE, que, pode estar relacionado, inclusive, à marcação de parâmetros nas duas variedades. Nesse sentido, Callou e Avelar (2012) salientam que o uso do verbo ter pode ser interpretado de maneira diferenciada nas duas variedades, a saber, como possessivo no PE e como existencial no $\mathrm{PB}$, como se verifica em sentenças com sujeito nulo, conforme exemplos $(12)^{9}$.

(12) a. Tem várias calças dentro do armário.

PE: 'Ele/Ela tem diversas calças dentro do armário' PB: 'Há várias calças dentro do armário'

b. Tinha um documento na carteira.

PE: 'Ele/Ela tem um documento dentro na carteira' PB: 'Há um documento dentro da carteira'

c. Tem dois computadores no escritório.

PE: 'Ele/Ela tem dois computadores no escritório' PB: 'Há dois computadores no escritório'

\footnotetext{
7 Usa-se este termo com o significado de "fala de pessoas sem nível superior completo".

${ }^{8}$ Salienta-se que a variável estudada pela autora era ternária, pois a mesma considerou também o verbo ver, conforme seu exemplo: "Você vê muito concreto na tua frente", variando com "Há/Tem muito concreto na tua frente", por essa razão os percentuais não contabilizam $100 \%$.

9 Os exemplos (12), (13) e (14) foram extraídos de Callou e Avelar (2012, p. 225-226), em cujo estudo estão numerados, respectivamente, (01) (02) e (03).
}

Essa diferença interpretativa, segundo apontam os autores, não ocorre quando o sujeito estiver expresso ou quando a frase for com o verbo haver:

(13) Ele tem várias calças dentro do armário. $\mathrm{PE} / \mathrm{PB}:$ 'Ele/Ela tem diversas calças dentro do armário.

(14) Há várias calças dentro do armário. PB/PE: 'Há diversas calças dentro do armário'

Esses mesmos pesquisadores, em artigo anterior, Callou e Avelar (2000), sugerem que um forte candidato a acionar a reanálise de ter como verbo existencial é a redução das flexões no paradigma verbal no PB, a qual teve uma drástica consequência no uso de sujeitos referenciais nulos, tornando os contextos para tal uso restritos. Os autores estabelecem, até mesmo, um paralelo temporal entre o uso de ter-existencial e a perda do sujeito nulo, detectada no final do século XIX (DUARTE, 1995; TARALLO, 1993). Desse modo, coadunando com os autores, podemos afirmar que a implementação de ter-existencial no PB se encaixa em um conjunto maior de mudanças por que vem passando o PB. Em outras palavras, o amplo uso de haver por ter no PE pode estar relacionado com o fato de aquele só selecionar um argumento interno e nunca um sujeito de referência definida, em conformidade com a hipótese plausível e empiricamente motivada, postulada por Callou e Avelar (2000, p. 97).

Não se detendo em explicações estruturais/paramétricas, e atendendo aos propósitos desta seção, cabe notar que o uso de ter/haver é frequentemente apontado como um dos aspectos que distinguem a norma brasileira da europeia (MIRA MATEUS et al., 1989; 2006). Nesse sentido, Eleutério (2003), com base em dados orais do PE, afirma que é detectado o uso de ter-existencial na variedade europeia, mas o haver é majoritário, com 
uma frequência de uso expressiva, na ordem de $80 \%$. Essa frequência de uso para o verbo haver-existencial aproxima-se do que tem sido encontrado sobre esse uso do verbo haver em textos escritos no $\mathrm{PB}$, algo que revela o conservadorismo da expressão escrita do PB, ainda seguidora da norma europeia. Para exemplificar essa afirmação, cita-se o trabalho de Vitório (2013) que, ao analisar os verbos ter e haver existenciais na fala e na escrita de 64 crianças alagoanas entre 7 e 12 anos, encontrou $88 \%$ de ter, nos dados orais, e 7\%, nos escritos. Também Avelar (2006) aponta que o uso de ter na língua escrita brasileira aparece com uma frequência de $8 \%$ entre os séculos XVI-XVIII, $22 \%$ no século XIX e $30 \%$ no século XX, apontando que esses resultados não revelam de fato o que realmente acontece na língua falada, em que é notável a preferência pelo verbo ter.

Para finalizar este breve panorama da variação ter/haver existenciais no PB e no PE, destaca-se que o estudo de Vitório (2010), realizado com base na fala espontânea de 64 crianças alagoanas, excluindo expressões cristalizadas, como "tem horas", "tem vezes", "tem dias" e os contextos opacos, encontrou apenas 7 ocorrências de haver em um total de 169 dados (ou seja, um percentual de 4\%), sendo essas ocorrências repetições das perguntas do adulto (que funcionam com trigger). Esses resultados levam a se postular que o verbo ter é o verbo naturalmente selecionado pela criança em seu processo de aquisição da linguagem, "sugerindo que haver não faz mais parte desse processo, não existindo assim a variação ter/haver existenciais na gramática nuclear dos falantes do português brasileiro, mas sim na gramática periférica" (VITÓRIO, 2010, p. 62). Os resultados da pesquisa da autora podem ser contrastados com os obtidos por Magalhães (2006), que mostra que crianças portuguesas, aos dois anos de idade, já produzem sentenças com haver existencial, ao contrário das brasileiras, que, até os três anos, só constroem sentenças com ter.

\section{Análise variacionista: ter e haver no português falado em Luanda-Angola}

\subsection{Palavras iniciais: os estudos sobre variedades africanas do português}

É sabido que, desde o final do século XIX e início do século XX, dialetólogos e interessados em assuntos da linguagem estabeleciam um paralelo entre o $\mathrm{PB}$ e o $\mathrm{PE}$, principalmente à medida que iam se delineando peculiaridades que diferenciavam essas duas variedades nacionais. Com o surgimento e consolidação da Linguística no Brasil, esses fatos passaram a ser investigados com base numa análise baseada em dados reais e, como apontam Oliveira et al. (2015), firmou-se, a partir de então, uma dicotomia PB/PE, tendo resultado na publicação de inúmeros trabalhos nessa direção, embasados em diferentes vertentes teórico-metodológicas. Nesse sentido, é importante frisar que, não obstante a importância dessas pesquisas para o desvelamento da identidade linguística brasileira, é igualmente salutar o cotejo entre o português europeu e o português falado em outras excolônias portuguesas, a exemplo das variedades faladas em alguns países africanos ${ }^{10}$.

Essas pesquisas são importantes, visto que podem trazer elementos para a discussão sobre a formação do PB, averiguando, por exemplo, o papel do contato da língua portuguesa com línguas africanas. Igualmente são importantes para as pesquisas que investigam as línguas do ponto de vista das suas estruturas, pois possibilitam a compreensão acerca da gramática da língua portuguesa.

${ }^{10}$ Alguns autores já salientaram essa importância e já realizaram estudos nessa perspectiva, a exemplo de Inverno (2004), Petter (2007). Teixeira (2008, 2013), Araujo (2010), Brandão e Vieira (2012), de Inverno (2004), Petter (2007), Teixeira (2008, 2013), Araujo (2010), Brandão e Vieira (2012), Figueiredo e Oliveira (2013), entre outros. Assim, passado o período de comparação PB/PE e também variedade brasileira com as das ex-colônias portuguesas na África. 
No caso específico deste trabalho, as atenções são voltadas para o português luandense, isto é, para o português falado na capital da província de Luanda, também capital de Angola. Não são feitos diretamente contrastes com dados do PB, embora sejam utilizados os resultados de pesquisas sobre os verbos ter e haver no PB, estes tomados para que se proceda, en passant, a um cotejo entre as duas variedades do português, a brasileira e a angolana, essa apontada na literatura como ainda em formação (TEIXEIRA, 2008, 2013) ou como já possuidora de uma identidade própria (FIGUEIREDO; OLIVEIRA, 2013).

Em termos da importância sócio-histórica dos estudos linguísticos com dados de variedades de ex-colônias portuguesas, a realidade linguística angolana é incontestavelmente salutar para os estudos sobre a formação do $\mathrm{PB}$, tendo em vista que houve a presença de negros africanos escravizados durante mais de três séculos no Brasil, que vinham em grande número de Angola. Por isso, as pesquisas sobre a variedade angolana devem ser reforçadas, como explica Teixeira (2008, p. 02):

Nos primeiros séculos de colonização do Brasil, a mão-de-obra escrava africana provinha majoritariamente da área onde ficam hoje a República do Congo e Angola - região em que predominam as línguas nativas do grupo banto. Por outro lado, a interação de brasileiros e angolanos em Luanda, desde o século XVII, quando as relações comerciais entre eles se estabeleceram de forma intensa e continuada, corrobora a necessidade de uma guinada nessa direção ${ }^{11}$.

\subsection{A comunidade de fala: Luanda-Angola}

Luanda abriga uma grande diversidade linguística, sendo o português a língua oficial do país, convivendo com diversas línguas africanas do grupo banto, a exemplo do kikongo, do kimbundo e do umbundo. Além do contato

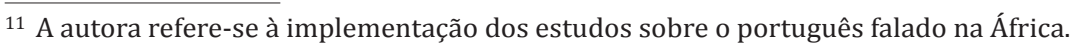

entre línguas diversas, a história de contatos dialetais ${ }^{12}$ é uma tônica na cidade, pelo fato de ter recebido muitas pessoas de diferentes partes do país, em busca de segurança e de trabalho, principalmente a partir das lutas pela independência, nos anos de 1961 a 1975 e da Guerra Civil, que se estendeu de 1975 a 2002. Nesse sentido, segundo informam Teixeira e Almeida (2011), nos dias atuais, em decorrência desses fluxos migratórios, "é difícil lá encontrar um falante monolíngue de qualquer das línguas nacionais em meio aos seus 5 milhões de habitantes" (TEIXEIRA; ALMEIDA, 2011, p. 6).

Os primeiros portugueses chegaram ao território onde atualmente fica a República de Angola em 1575. Buscavam as minas de prata e ocuparam militarmente a costa em direção à barra de Quanza, de onde seguiriam em busca das minas. A eles se juntou um grupo de portugueses que teria sido expulso do Reino do Congo. Muitos desses portugueses dos primeiros tempos não suportaram as adversidades e morreram, como informa Pepetela $(1990$ apud Teixeira, 2008, p. 04), que afirma que dos 2.340 soldados entrados entre 1575 e 1592, restavam no final do período apenas 300, tendo, a sua maioria, sido vítima de doenças.

Como as expectativas em torno das minas de prata não foram bem sucedidas, os portugueses foram em busca de escravos, negócio que cresceu rapidamente, transformando Luanda em uma feitoria, um simples ponto de apoio para a guarda e embarque das "peças", das quais muitos viam ao Brasil.

Houve uma política de divulgação da língua portuguesa em Angola. Os portugueses criaram, inclusive, um grupo de apoio, chamado Assimilados ${ }^{13}$. Aos filhos destes era dado o direito de frequentar a escola e a nacionalidade

${ }^{12}$ A expressão "contatos dialetais" foi utilizada para enfatizar que existem também variedades espaciais dessas línguas.

13 Os Assimilados, inicialmente, tinham a função de incentivar a adoção da cultura europeia, consequentemente, da língua portuguesa, em detrianto da cultura línguas africanas. Mais tarde, esse grupo de apoio voltou-se contra o governo colonial e liderou a luta pela independência do país. 
portuguesa. O domínio da língua portuguesa e a assimilação de hábitos da cultura europeia eram cruciais para se galgar um cargo administrativo ou qualquer outra função no governo. Consequentemente, os "nativos" foram cada vez mais afastados da vida da comunidade, na medida em que o próprio governo não oferecia condições para a sua inclusão social:

Assim, a situação linguística refletia a divisão social: a maioria da população falava kimbundo; os assimilados eram bilíngues, e só a uma parcela mínima da população, representada por portugueses, falavam unicamente o português. (TEIXEIRA; ALMEIDA, 2011, p. 103).

A população mais jovem, os filhos dos assimilados adquiriam o português como primeira língua (L1). Daí em diante, foi crescendo o número de angolanos falantes nativos do português. Após décadas de luta patrocinada por parte dos assimilados, como também por alguns descendentes de portugueses, a situação linguística de Luanda muda consideravelmente: a maior parte de população é bilíngue (português/kimbundo), uma parte considerável é monolíngue (português) e uma menor parte o é em kimbundo. (MINGAS, 2000).

\subsection{A amostra}

As entrevistas de onde foram levantados os dados desta pesquisa pertencem ao acervo linguístico dos projetos "Em busca das raízes do português brasileiro" e "A concordância verbal em Luanda-Angola: elementos para a discussão sobre a formação do português brasileiro"14, ambos sediados no Núcleo de estudos da língua Portuguesa da UEFS (NELP/UEFS), com entrevistas já gravadas e transcritas.

\footnotetext{
${ }^{14}$ Para a realização das entrevistas, houve a submissão ao Comitê de Ética em Pesquisa com Seres Humanos (CEP/UEFS) 0 número do Parecer favorável à sua realização é 140.511. 0 segundo projeto é um subprojeto do primeiro, de modo que as entrevistas são as mesmas.
}

Os critérios utilizados para a seleção dos informantes foram: sexo/gênero (Masculino e Feminino); faixa etária (I - 20 a 30 anos, II - 36 a 50 anos e III - acima de 52); escolaridade (Baixa ou nula e Superior) ${ }^{15}$; língua nativa (Português e Línguas africanas); local de nascimento (Capital e Interior). Sendo assim, deveriam existir 24 informantes (sendo 4 informantes por faixa etária, dois homens e duas mulheres), mas não se encontrou ainda uma mulher da faixa I com escolaridade superior que atenda aos critérios de ser falante de línguas africanas e de ter nascido no interior.

Assim, a amostra conta com informantes distribuídos nos dois sexos, com níveis de escolaridade que se relacionam às duas principais normas do português luandense (PL) - normas popular e culta (LUCCHESI, 2001, 2015, entre outros) - em três faixas etárias, composta de falantes nativos de português e de línguas nacionais, além de naturais da capital e do interior da província de Luanda.

\subsection{A análise variacionista: percurso investigativo e a análise descritiva}

Embora se intentasse pesquisar a variação com a concordância verbal de número com os verbos ter e haver em construções existenciais, investigando a possibilidade de concordância do verbo com o SN tradicionalmente analisado como objeto direto, em sentenças como "Tinha/tinham/havia/ haviam muitas dúvidas", isso não foi possível, devido a escassez de dados com verbos com argumento interno plural. Apenas foram encontrados 131 dados, em que o argumento interno era de número plural, como se observa nos exemplos (15) a (19), pois a maioria era com o SN singular, tal como se verifica em (20) e (21):

${ }^{15}$ Consideraram-se os extremos do continuum sociolinguístico brasileiro, a saber, a variedade linguística falada por pessoas analfabetas ou parcamente escolarizadas (até 4 anos de escolarizaça) e por pr com escolarizaça superior. Essa escolha metodológica justifica-se pela intenção de se contrapor com escolarização superior. Essa escolha metodologica justifica-se pela intenço de se contrapor a $(1994,2015)$ é, além de heterogênea, bipolarizada. 
(15) [...] há pessoas que sabem falar português bem, e não lê. (Informante A: sexo feminino; faixa II; baixa escolaridade; falante do Umbundo como L1; natural do interior de Luanda)

(16) [...] então havia também umas minhas vizinhas também. (Informante A: sexo feminino; faixa II; baixa escolaridade; falante do Umbundo como L1; natural do interior de Luanda)

(17) [...] Ali tinha no quintal duas casa de cinema até. (Informante B: sexo feminino; faixa III; baixa escolaridade; falante do português como L1; natural de Luanda)

(18) Tem vezes que faço... fizemos o contrário. (Informante C: sexo feminino; faixa I; nível superior incompleto; falante do português como L1; natural de Luanda)

(19) [...]...tinha uns bichinhos que eles fala que é minhoca. (Informante D: sexo masculino; faixa I; baixa escolaridade; falante do Umbundo como L1; natural do interior de Luanda)

(20) Tem aí essa novela da madrasta... isso tudo eu gosto. (Informante D: sexo masculino; faixa I; baixa escolaridade; falante do Umbundo como L1; natural do interior de Luanda)

(21) Não tem saldo no telemóvel pra ligar pra minha filha. (Informante B: sexo feminino; faixa III; baixa escolaridade; falante do português como L1; natural de Luanda)

Desses dados com argumento interno plural, apenas foram identificados dois dados em que havia a concordância plural, as duas com o verbo ter. Foram os seguintes dados, levantados na fala de uma única:

(22) Ali, era... tinha uma casa... Tinham duas até. (Informante B: sexo feminino; faixa III; baixa escolaridade; falante do português como L1; natural de Luanda)

(23) [...] dentro do quintal tinham duas casas de cinema. (Informante B: sexo feminino; faixa III; baixa escolaridade; falante do português como L1; natural de Luanda)
Dando seguimento à investigação, procedeu-se a uma pesquisa em torno dos verbos ter e haver, com o objetivo inicial de investigar em quais tipos de estruturas ocorriam as formas verbais com esses dois verbos no português luandense. Foram consideradas as seguintes estruturas, cujos exemplos, retirados do corpus, se seguem:

I - Verbos plenos (posse) ${ }^{16}$ :

(24) [...] se eu tivesse a pasta... (Informante E: sexo feminino; faixa I; baixa escolaridade; falante do português como L1; natural de Luanda)

II - Tempos compostos:

(25) [...] quando nasci meu pai já tinha falecido. (Informante F: sexo feminino; faixa I; baixa escolaridade; falante do Kikongo como L1; natural do interior de Luanda)

(26) ...o presidente que na altura havia ganhado as eleições, [...] (Informante C: sexo feminino; faixa I; nível superior incompleto; falante do português como L1; natural de Luanda)

\section{III - Estruturas modais:}

(27) [...] eu tenho que acordar antes das sete. (Informante E: sexo feminino; faixa I; baixa escolaridade; falante do português como L1; natural de Luanda)

(28) ...aquela guerrinha entre o velho e o novo há que existir sempre. (Informante G: sexo masculino; faixa I; nível superior completo; falante do português como L1; natural de Luanda)

IV - Verbos funcionais (verbo suporte ou leve) ${ }^{17}$ :

(29) Tenho medo de morrer (Informante D: sexo masculino; faixa I; baixa escolaridade; falante do Umbundo como L1; natural do interior de Luanda)

${ }^{16}$ Não foi encontrado exemplo com o verbo haver

17 Não foi encontrado exemplo com o verbo haver. 


\section{$\mathrm{V}$ - Existenciais:}

(30) Havia mais respeito, mais respeito, agora não. (informante H: sexo feminino; faixa II; nível superior incompleto; falante do português como L1; natural de Luanda)

(31) Não tem ninguém pra ir reclamar. Você reclama dentro do táxi [...] (Informante F: sexo feminino; faixa I; baixa escolaridade; falante do Kikongo como L1; natural do interior de Luanda)

VI - Existencial indicando tempo decorrido ${ }^{18}$ :

(32) As guerras iniciou há muito tempo. (Informante A: sexo feminino; faixa II; baixa escolaridade; falante do Umbundo como L1; natural do interior de Luanda)

A distribuição dos dados é apresentada a seguir (Tab. 1). Como se vê, apenas nos resultados percentuais com as estruturas existenciais, em negrito, verifica-se um processo de variação estruturada com regras, de fato, variáveis:

Tabela 1 - Verbos ter e haver no português luandense em diferentes tipos de estruturas

\begin{tabular}{lcccc}
\hline & \multicolumn{2}{c}{ Ter } & \multicolumn{2}{c}{ Haver } \\
\cline { 2 - 5 } & No ocorrências/Total & \% & № ocorrências/Total & \% \\
Posse & $540 / 540$ & 100 & $0 / 0$ & 0 \\
Tempos composto & $92 / 95$ & 96,8 & $3 / 95$ & 3,2 \\
Modal & $306 / 315$ & 97,1 & $9 / 315$ & 2,9 \\
Funcional & $34 / 34$ & 100 & $0 / 0$ & 0 \\
Existencial & $160 / 381$ & $\mathbf{4 2 , 0}$ & $219 / 381$ & $\mathbf{5 8 , 0}$ \\
Tempo decorrido & $0 / 0$ & 0 & $36 / 36$ & 100 \\
\hline
\end{tabular}

${ }^{18}$ Não foi encontrado exemplo com o verbo haver.
A título de comparação com o português falado em outra ex-colônia portuguesa, salienta-se que Callou, Batista e Almeida (2015, p. 192), ao investigarem o Português de São Tomé (PST), concluíram que, assim como em PE, o haver predomina (92\%) sobre o ter-existencial ( $8 \%$-- 11/132), e o verbo não sofre flexão de número quando o argumento interno é [+ plural]. Assim, em termos percentuais de uso do ter existencial, o PST é diferente do PL e do PB, aproximando-se (o PST) do de Portugal.

\subsection{Ter e haver existenciais no português luandense: a análise variacionista}

A partir dos resultados expostos na Tabela 1, verifica-se que apenas ocorre variação de fato com os verbos ter e haver existenciais (estruturas impessoais). Em vista dessa constatação e da escassez de dados de flexão de plural nas construções existenciais, a pesquisa que objetivava analisar a concordância verbal de número com os verbos impessoais, teve o seu objeto de estudo modificado para a análise variacionista em torno dos verbos ter e haver com o valor existencial. Em outras palavras, buscou-se investigar quais são os contextos linguísticos e socioculturais que favorecem o uso de tais verbos nas construções existenciais. Nesse sentido, tendo em vista que a literatura aponta que o uso inovador em relação ao uso lusitano reside no uso do verbo ter existencial, esta foi a variante escolhida como regra de aplicação durante as "rodadas" realizadas com o programa estatístico Goldvarb X (SANKOFF; TAGLIAMONTE; SMITH; 2005). Foram controladas sete variáveis, sendo duas linguísticas e cinco socioculturais, conforme é exposto no Quadro 1, adiante.

Dos sete grupos controlados, quatro foram selecionados pelo Goldvarb $\mathrm{X}$ como relevantes para a implementação do verbo ter existencial, nesta ordem: escolaridade, tempo verbal, faixa etária e local de nascimento. 0 input inicial de aplicação da regra de ter existencial foi 0,42, o input final 
Quadro 1 - Variáveis consideradas na análise de ter e haver existenciais no português luandense

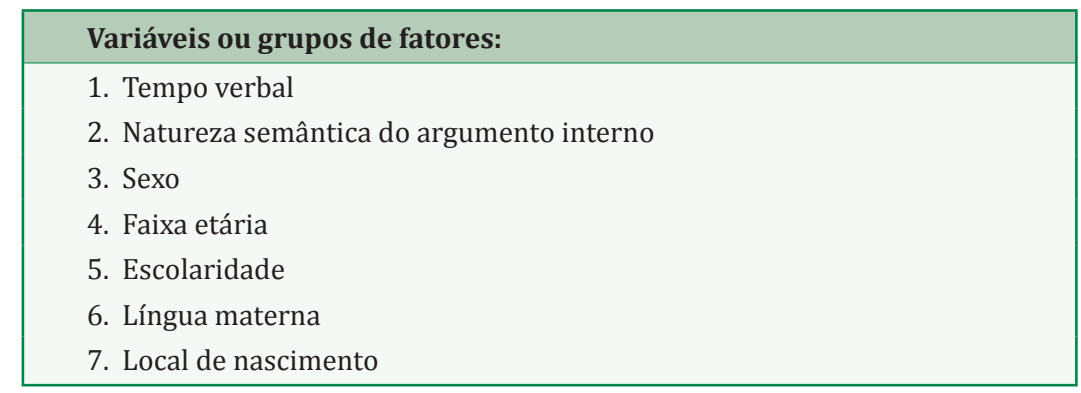

foi 0,41, o nível de significância foi 0,001 e o log likelihood foi -228.952. A seguir, são apresentados e discutidos os resultados para as variáveis selecionadas, seguindo-se a ordem de seleção.

\section{Escolaridade}

A variável escolaridade foi controlada tendo como hipótese a de que o ensino superior completo favoreceria o uso do verbo haver. Salienta-se, contudo, que o uso do verbo ter existencial não é estigmatizado, pelo menos no Brasil, sendo, na verdade, apenas um uso incentivado no ambiente escolar ${ }^{19}$. Assim, o uso de ter pode ser considerado um traço gradual não padrão, ao contrário, por exemplo, do uso da variante zero de plural da concordância verbal, que pode ser considerada traço não padrão abrupto ou descontínuo, termos utilizados com base na terminologia proposta por Bortoni-Ricardo (2011). Seguindo esse raciocínio, acredita-se que, influenciados por fatores linguísticos e estilísticos, informantes escolarizados podem usar a variante ter, mas, ao fazerem uso da escrita ou em situações formais de fala, optam

${ }^{19} \mathrm{Os}$ resultados de pesquisas com dados de escrita de estudantes, adiante comentadas neste texto, corroboram com esta afirmação. preferencialmente por haver, já que têm consciência das implicações sociais do uso de ambas as variantes.

Nesse sentido, o controle da variável escolaridade revelou um comportamento diferenciado no uso dos verbos ter e haver a depender da escolaridade do informante. Na Tabela 2, apresentam-se esses resultados:

Tabela 2 - Atuação da variável escolaridade no uso do verbo ter existencial no português luandense

\begin{tabular}{lccc}
\hline Fatores & Ocorrências/Total & \% & Peso Relativo \\
Baixa ou nula & $76 / 132$ & 57,6 & .63 \\
Ensino Superior & $84 / 249$ & 33,7 & .43 \\
Total & $160 / 381$ & 42 & \\
\hline
\end{tabular}

A partir da interpretação dos resultados expostos, já é possível presumir que o verbo ter existencial é mais utilizado por falantes analfabetos e/ou parcamente escolarizados. A frequência de ter, que em todo o corpus é de $42 \%$, aumenta para $57,6 \%$ na fala desses informantes. Já a frequência do verbo haver, que em todo o corpus é de $58 \%$, aumenta para $66,6 \%$ com os dados dos informantes cultos. Assim, tal como se verifica no PB, é na norma popular luandense ${ }^{20}$ que se verifica mais o uso do verbo ter, apresentando peso relativo no valor de 63 .

\section{Tempo verbal}

Inicialmente, pensou-se em controlar tempo e modos verbais conjuntamente. Porém, os resultados mostraram-se de difícil interpretação, como se lê na Tabela 3 a seguir.

${ }^{20}$ Adotou-se o conceito teórico da bipolarização de normas, proposto por Coseriu (1967) e Lucchesi (2001, 2015, entre outros) 
Tabela 3 - Atuação da variável tempo e modo verbais no uso do verbo ter existencial no português luandense

\begin{tabular}{lccc}
\hline Fatores & Ocorrências/Total & $\%$ & Peso Relativo \\
Subjuntivo (Presente, Futuro, & $13 / 23$ & 56,5 & .68 \\
Pretérito, Imperfeito) & $31 / 55$ & 56,4 & .67 \\
Pretérito imperfeito do Indicativo & $11 / 20$ & 55 & .65 \\
Infinitivo & $7 / 14$ & 50 & .63 \\
Pretérito Perfeito & $97 / 261$ & 37,2 & .43 \\
Presente do Indicativo & $1 / 7$ & 14 & .33 \\
Futuro do Indicativo & & 42 & - \\
Presente e Pretérito) & $160 / 380^{*}$ & 4 & - \\
\hline
\end{tabular}

*Foi retirado o único dado encontrado com verbo no particípio: “Na sua generalidade tem havido... er... er... muita [...]".

Assim, procedeu-se à recodificação dos dados, agrupando-os por tempo verbal (presente, passado, futuro, infinitivo). Os resultados obtidos estão na Tabela 4.

Tabela 4 - Atuação da variável tempo verbal no uso do verbo ter existencial no português luandense

\begin{tabular}{lccc}
\hline Fatores & Ocorrências/Total & $\%$ & Peso Relativo \\
\hline Passado & $44 / 77$ & 57,1 & .69 \\
Infinitivo & $11 / 20$ & 55 & .66 \\
Futuro & $7 / 17$ & 41,2 & .50 \\
Presente & $98 / 266$ & 36,8 & .43 \\
Total & $160 / 380$ & 42 & \\
\hline
\end{tabular}

Os resultados apontam para um favorecimento do verbo ter no tempo passado, algo que destoa do que demonstram a literatura. Callou e Avelar (2000, p. 91), por exemplo, ao investigarem a fala culta carioca com dados das décadas de 1970 e 1990, concluem que construções no passado favorecem o uso de haver, enquanto construções no presente favorecem o uso de ter, conforme expõem: "As construções no passado favorecem a ocorrência de haver, enquanto as no presente a de ter". Contudo, vale salientar que os referidos autores analisaram os dados do pretérito separadamente, sendo que o tempo perfeito revelou um aumento de peso relativo concernente ao verbo haver, conforme se vê na Tabela 5:

Tabela 5 - Peso relativo aos tempos verbais para a ocorrência de ter

\begin{tabular}{lcc} 
Tempo Verbal & Década de $\mathbf{7 0}$ & Década de $\mathbf{9 0}$ \\
Presente & .60 & .60 \\
Pretérito perfeito & .09 & .38 \\
Pretérito imperfeito & .44 & .45 \\
\hline
\end{tabular}

Fonte: Callou e Avelar (2000, p. 92).

Em vista dessa constatação, procedeu-se à investigação dos verbos com um refinamento dos fatores, codificando os dados do pretérito separadamente (imperfeito e perfeito) e também decidiu-se excluir os dados do verbo no infinitivo e do futuro, a fim de possibilitar uma melhor comparação dos resultados com os resultados obtidos por outros pesquisadores. Os resultados dessa recodificação estão na Tabela 6.

Tabela 6 - Atuação da variável tempo verbal no uso do verbo ter existencial no português luandense, após recodificação dos dados

\begin{tabular}{lccc}
\hline Tempo Verbal & Ocorrências/Total & Frequência (\%) & Peso Relativo \\
Presente & $98 / 266$ & 36,8 & .44 \\
Pretérito perfeito & $22 / 39$ & 56,4 & .75 \\
Pretérito imperfeito & $22 / 38$ & 57,9 & .60 \\
\hline
\end{tabular}

Input 0.397; Log likelihood $=-200.129 ;$ Significance $=0.041$. 
Como se nota na Tabela 6, não houve mudança em relação aos resultados expostos na Tabela 4, sendo mesmo o tempo presente o desfavorecedor do verbo ter e não se identificou uma diferença entre o perfeito e o imperfeito. A seleção das demais variáveis se mantiveram, razão pela qual se prosseguiu a discussão considerando a primeira codificação dos dados.

Sobre a atuação dos tempos verbais, Marins (2013, p. 69), ao investigar as sentenças existenciais com os verbos haver e ter no PB e no PE ao longo da segunda metade do séc. XIX até o séc. XX, tendo como corpora peças de teatro, constatou - tal como Callou e Avelar (2000) - que, no PB, o pretérito perfeito é muito utilizado com o verbo haver, sendo o presente o tempo em que mais o verbo ter é utilizado, o contrário dos resultados obtidos neste estudo.

Gráfico 1 - Distribuição de ter e haver pelos tempos verbais a partir da segunda metade do século XX (PB)

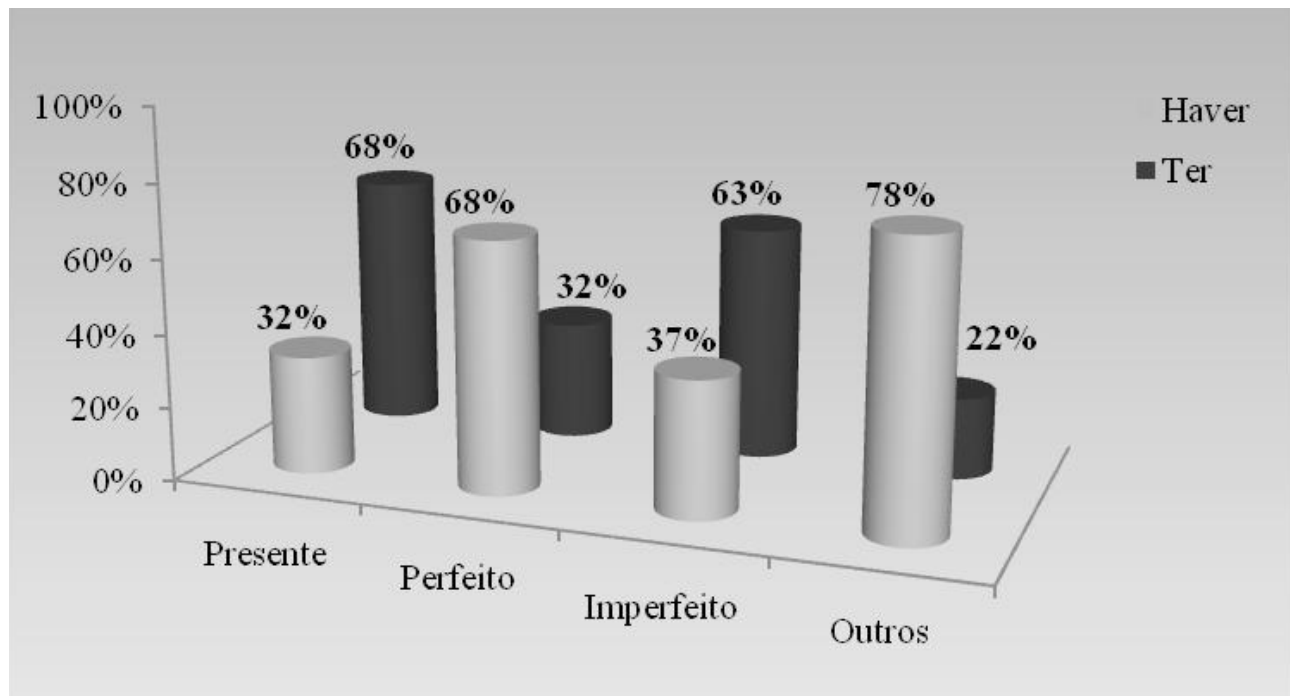

Fonte: Marins (2013, p. 83)
A propósito, neste estudo, mesmo tendo sido realizada outra rodada, acrescentando o fator "outros verbos" para abrigar os dados de futuro e de infinitivo, os tempos verbais no passado continuaram a desfavorecer o uso do verbo ter, algo que pode revelar um comportamento diferenciado do português luandense em relação ao PB. A Tabela 7 traz esses resultados.

Tabela 7 - Atuação da variável tempo verbal no uso do verbo ter existencial no português luandense, após recodificação dos dados com base em Marins (2013)

\begin{tabular}{lccc}
\hline Tempo Verbal & Ocorrências/Total & Frequência (\%) & Peso Relativo \\
Presente & $98 / 266$ & 36,8 & .43 \\
Pretérito perfeito & $22 / 39$ & 56,4 & .76 \\
Pretérito imperfeito & $22 / 38$ & 57,9 & .62 \\
Outros verbos & $17 / 38$ & 44,7 & .55 \\
\hline
\end{tabular}

Input 0.402; Log likelihood $=-228.476$; Significance $=0.004$.

\section{Faixa etária}

O binômio Variação-Mudança pode ser escrutinado por meio do controle da variável faixa etária, permitindo que se façam projeções históricas acerca do fenômeno variável. Geralmente, julga-se que os mais jovens usam mais a forma considerada inovadora não padrão, enquanto os mais velhos usam mais a forma conservadora padrão. Tal afirmação, obviamente, não pode ser tomada como geral, uma vez que os estudos sociolinguísticos devem partir da consideração das particularidades que envolvem o fenômeno em análise, além das particularidades da comunidade de fala. Por conseguinte, é preciso ter em conta que nem sempre "inovar" é sinônimo de "afastar-se da norma padrão"; basta, por exemplo, considerar os resultados das comunidades rurais afrobrasileiras estudadas por Lucchesi, Baxter e Silva (2009), em que se vê um maior uso da variante padrão de concordância verbal na fala dos informantes mais jovens, atestando que essa é a forma inovadora na comunidade. 
Por conseguinte, destaca-se que, no modelo sociolinguístico, a análise empreendida com base no fator faixa etária é muito importante, já que, por meio do recurso do tempo aparente, analisa-se se os casos de variação refletem uma variação estável (coexistência de formas intercambiáveis no sistema linguístico) ou mudança em progresso (concorrência entre as variantes, com tendência de permanência de apenas uma delas). Ao utilizar o recurso do tempo aparente, o pesquisador baseia-se no pressuposto de que diferenças linguísticas entre gerações podem espelhar desenvolvimentos diacrônicos, desde que outros fatores se mantenham inalterados; por isso, é necessário observar a sócio-história da comunidade.

Quanto aos resultados obtidos neste estudo, foi constatado que são as faixas etárias mais jovens (as Faixas 1 e 2) que favorecem o uso do verbo ter, sugerindo um caso de mudança em progresso. A seguir, são expostos os resultados relativos ao controle da faixa etária do informante:

Tabela 8 - Atuação da variável faixa etária no uso do verbo ter existencial no português luandense

\begin{tabular}{lccc}
\hline Fatores & Ocorrências/Total & $\%$ & Peso Relativo \\
Faixa 1 (20 a 30 anos) & $59 / 124$ & 47,6 & .64 \\
Faixa 2 (36 a 50 anos) & $69 / 138$ & 50 & .54 \\
Faixa 3 (acima de 52) & $32 / 119$ & 26,9 & .32 \\
Total & $160 / 381$ & 42 & \\
\hline
\end{tabular}

Constata-se que o menor índice de aplicação do verbo ter concentra-se na faixa etária mais alta (faixa 3), ou seja, os idosos de Luanda usam mais o verbo haver. Assim, há o favorecimento da aplicação da regra de ter apenas nas faixas mais jovens, mas com um valor mais significativo na faixa 1 (.64). O Gráfico 2 ilustra de forma mais nítida o comportamento dos informantes luandenses, com os valores dos pesos relativos no que diz respeito ao uso de ter existencial em função da faixa etária dos informantes:
Gráfico 2 - Atuação da faixa etária no uso do verbo ter existencial no português luandense (pesos relativos)

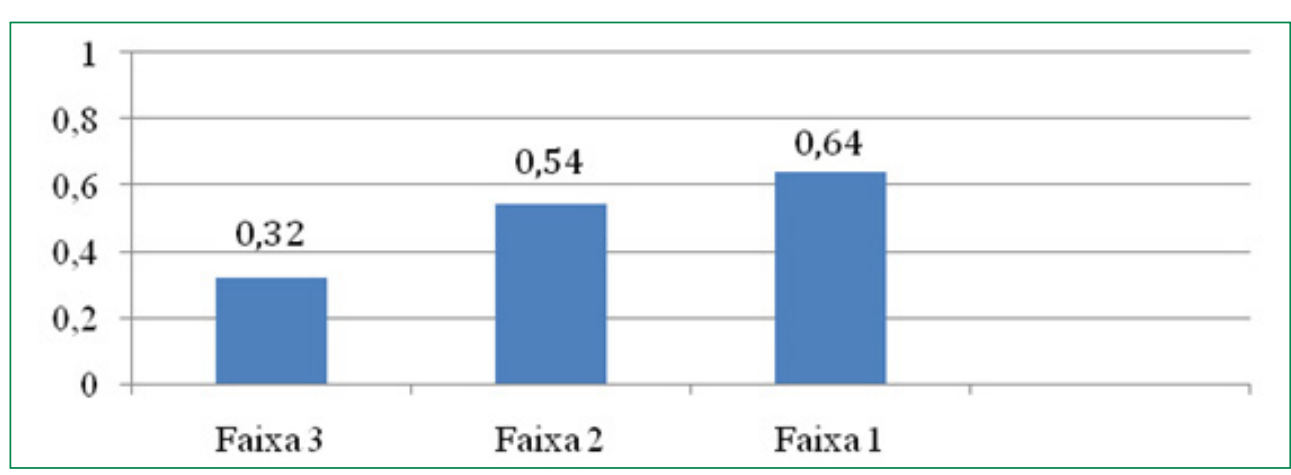

Dado o exposto, é possível afirmar que, em termos de construção existencial, a variável inovadora é o verbo ter, de modo que são os informantes da faixa 3 os únicos que mantêm o uso de haver existencial. Salienta-se que os resultados dizem respeito aos dados conjuntamente, isto é, normas popular e culta. Nesse sentido, considerando que a escolaridade reflete histórias sociolinguísticas distintas, foi feito o cruzamento das variáveis faixa etária e escolaridade, a fim de investigar se havia tendências diferenciadas no rumo da variação/mudança. Os resultados estão expostos na Tabela 9.

Tabela 9 - Frequência do uso de ter existencial no português luandense segundo o cruzamento das variáveis escolaridade e faixa etária

\begin{tabular}{lccc}
\hline Escolaridade & Faixa Etária & Ocorrências/Total & $\%$ \\
Baixa ou nula & Faixa 1 & $29 / 41$ & 71 \\
(norma popular) & Faixa 2 & $39 / 68$ & 57 \\
& Faixa 3 & $8 / 23$ & 35 \\
Superior & Faixa 1 & $30 / 83$ & 36 \\
(norma culta) & Faixa 2 & $30 / 70$ & 43 \\
& Faixa 3 & $24 / 96$ & 25 \\
Total & & $160 / 381$ & 42 \\
\hline
\end{tabular}


Desse modo, vislumbra-se, na fala luandense, uma realidade próxima ao que ocorre nos processos de mudança "de baixo para cima", já que se observa o contexto de menor resistência nas faixas etárias mais jovens (para o uso da variante considerada inovadora). Cabe interpretar o fato de, na fala dos menos escolarizados (norma popular), o uso mais comum entre os informantes da faixa 3 ser o verbo haver. Em outras palavras, acerca do fato de ser essa variante dos verbos existenciais o uso tradicional/conservador. Sobre isso, aventa-se a hipótese de que como o português angolano ainda está em formação, tendo o país se livrado do jugo português há pouco tempo, os informantes da faixa 3 foram os que estiveram em maior contato com os portugueses no período da colonização, e estes, como afirmado na seção 2 deste texto, utilizam mais o verbo haver.

\section{Local de nascimento}

Os resultados obtidos com o controle da variável local de nascimento do informante foram ao encontro da hipótese formulada neste estudo. Tais resultados revelaram que os informantes que nasceram no interior do país utilizam mais a variante não padrão, ou seja, o ter existencial, algo que pode ser interpretado pelo fato de terem os informantes do interior da província de Luanda tido menos contato com os portugueses, já que estes se concentravam mais na capital do país. Na Tabela 10, são apresentados os resultados:

Tabela 10 - Atuação da variável local de nascimento do informante no uso do verbo ter existencial no português luandense

\begin{tabular}{lccc}
\hline Fatores & Ocorrências/Total & $\%$ & Peso Relativo \\
Interior & $96 / 192$ & 50 & .60 \\
Capital & $64 / 189$ & 33,9 & .40 \\
Total & $160 / 381$ & 42 & \\
\hline
\end{tabular}

Conclui-se, pois, que a variação ter e haver existencial é, sobretudo, condicionada por fatores socioculturais. Neste estudo, foram selecionadas como relevantes as variáveis extralinguísticas Escolaridade, Faixa etária e Local de nascimento do informante. A única variável linguística que se mostrou relevante foi o tempo verbal. A variável Natureza semântica do SN argumento interno, por exemplo, não foi selecionada.

\section{Considerações finais}

Este estudo teve como objetivo principal estender a análise da variação dos verbos ter e haver existenciais, considerando também a língua portuguesa de variedades africanas, especificamente o português falado em Luanda-Angola. Nesse sentido, correlacionando os resultados obtidos com as questões históricas e contrastivas expostas nas seções $1 \mathrm{e}$ 2, podem ser feitas algumas considerações. Destaca-se, inicialmente, que a substituição do haver por ter em contexto de posse já ocorria desde o século XVI na língua portuguesa, estando essa mudança concluída na língua portuguesa, quer na variedade brasileira, europeia ou luandense. Por outro lado, essa convergência não é verificada no que concerne ao sentido existencial, pois o PB e o PL assemelham-se e diferem em relação ao PE. Contudo, a propósito dessa semelhança, verifica-se uma diferença no padrão de uso no que concerne à norma popular luandense, a partir dos resultados revelados a partir da variável Faixa etária (cf. Tabelas 8 e 9). O verbo haver, forma padrão, é favorecido na fala dos informantes mais idosos (faixa III), algo que destoa dos estudos com dados de fala popular brasileira (VIEIRA, 1995, entre outros), em que a forma padrão é mais frequente e favorecida pelos mais jovens. Atribuiu-se esse resultado ao fato de o português luandense ainda está em formação (INVERNO, 2004, TEIXEIRA, 2008). 
Nesse sentido, quanto à análise variacionista realizada, os resultados expostos na Tabela 1 revelaram que a única estrutura em que ocorre uma variação estruturada com esses dois verbos é com a estrutura existencial (em sentenças impessoais). Detectou-se que o verbo ter é bastante usado em Luanda, embora o verbo haver ainda seja predominante (58\%). Porém, quando foram analisados os dados isoladamente, por subamostra investigada, ou seja, os dados dos analfabetos ou parcamente escolarizados versus dos escolarizados, respectivamente, normas popular e culta luandense, observou-se que, na norma popular, não é tão frequente a dicotomia ter/haver, estando as frequências de uso próximas (57,6\% de ter e 42,4\% de haver); ao contrário do que se verifica na norma culta, em que há uma realidade bipolarizada $\left(33,4 \%\right.$ de ter contra $66,6 \%$ de haver ${ }^{21}$.

Os informantes mais jovens são os que mais usam a variante inovadora (ter existencial), resultado que aponta para uma possível mudança em progresso. 0 cruzamento das variáveis escolaridade e faixa etária indicou que são os informantes com baixa ou nula escolaridade os que mais usam o verbo ter. Se essa frequência de uso se mantiver na comunidade, pode uma mudança se concretizar no português luandense, a favor da regra de ter existencial.

Em termos da descrição da variedade luandense, os resultados da variação ter e haver existenciais encontram paralelos com os obtidos em outros estudos realizados com dados no PB, haja vista que, tanto no PL quanto no PB, verifica-se, por exemplo, um maior uso do ter na fala de pessoas com pouca ou nenhuma escolarização. Nesse sentido, essa convergência entre as duas variedades do português destoa dos resultados obtidos em pesquisas realizadas sobre a concordância verbal de número no português luandense (ARAUJO, 2010, ARAÚJO; LUCCHESI, 2016, e ARAUJO, 2016), pois, nesses

${ }^{21}$ Remete-se o leitor para os resultados expostos na Tabela 2. estudos, detectou-se um contraste entre o PB e o PL, sendo detectada uma predominância da concordância padrão na fala luandense (inclusive entre usuários da norma popular), ao contrário do que ocorre no PB popular. Desse modo, ora o PL se aproxima do PB, ora se afasta. Assim, nem sempre se observa a mesma evolução nas diferentes variedades continentais da língua portuguesa, conforme concluiu Callou $(2009,2012)$ sobre o PB e o $\mathrm{PE}$, atestando que ora essas variedades são semelhantes, ora diferentes, dependendo do fenômeno linguístico em questão.

\section{Referências}

ARAÚJO, Silvana Silva de Farias. O uso variável da concordância verbal no português do Brasil (PB) e no português de Angola (PA): a história externa em foco. In: COLÓQUIO DA LUSOFONIA, 13., e ENCONTRO AÇORIANO, 5., 2010, Florianópolis. Atas do... Florianópolis, 2010.

A concordância verbal nos continua sociolinguísticos do português brasileiro e do luandense. Interdisciplinar: Revista de Estudos em Língua e Literatura, v. 24, n. 1 , p. 25-46, 2016.

ARAUJO, Silvana Silva de Farias; LUCCHESI Dante. Um estudo contrastivo sobre a concordância verbal em Feira de Santana e em Luanda. Papia, v. 26, n. 1, p. 71-99, 2016.

AVELAR, Juanito. De verbo funcional a verbo substantivo: uma hipótese para a supressão de HAVER no português brasileiro. Letras de Hoje, Porto Alegre, v. 41, n. 1, p. 49-74, 2006.

BORTONI-RICARDO, Stella Maris. Do campo para a cidade: estudo sociolinguístico de migração e redes sociais. São Paulo: Parábola Editorial, 2011.

BRANDÃO, Silvia Figueiredo; VIEIRA, Silvia Rodrigues. A concordância nominal e verbal no Português do Brasil e no Português de São Tomé: uma abordagem sociolinguística. Papia, v. 22, n. 1, p. 7-39, 2012.

CALLOU, Dinah Maria Isensee. A propósito de norma, correção e preconceito: do presente para o passado. Cadernos de Letras da UFF, v. 36, n. 1, p. 57-73, 2008.

Sobre variação e mudança no português do Brasil: aspectos morfossintáticos In: LOBO, Tania et al. (Org.). Linguística histórica, história da língua e outras histórias. Salvador/BA: EDUFBA, 2012. v. 1, p. 155-170. 
CALLOU, Dinah Maria Isensee; AVELAR, Juanito. Sobre ter e haver em construções existenciais: variação e mudança no português do Brasil. Gragoatá (UFF), UFF, v. 9, n. 2, p. $85-100,2000$.

Preservação e Mudança na História do Português: de Possessivo a Existencial. Matraga (Rio de Janeiro), v. 19, n. 30, p. 224-235, 2012.

CALLOU, Dinah Maria Isensee; ALMEIDA, Erica. Mudanças em curso no português brasileiro: contrastando duas comunidades. Textos selecionados XXIV Encontro Nacional da APL. Lisboa: Colibri Artes Gráficas, p. 161-168, 2009.

CALLOU, Dinah Maria Isensee; BATISTA, Priscila; ALMEIDA, Erica. Houveram/tiveram muitas reuniões': Construções existenciais e concordância verbal. Cuadernos de la ALFAL, v. 7, p. 185-194, 2015.

COSERIU, Eugeniu. Sistema, norma y habla. In: Teoria del lenguaaje y lingüística general. Madrid: Gredos, 1967.

COSTA, Maria João. Os verbos "aver" e "teer" no português arcaico - breve sinopse. Filologia e linguística portuguesa, v. 12, n. 1, p. 59-68, 2010.

DUARTE, Maria Eugênia Lamoglia. A perda do princípio "Evite Pronome" no português brasileiro. 1995. 161 f. Tese (Doutorado) - Universidade de Campinas, UNICAMP, 1995.

O sujeito expletivo e as construções existenciais. In: RONCARATI, Claudia; ABRACADO, Jussara (Org.). Português Brasileiro: contato lingüístico, heterogeneidade e história. Rio de Janeiro: 7 Letras, 2003. p. 123-131.

ELEUTÉRIO, Silvia. A variação ter/haver: documentos notariais do século XVII. Tese (Doutorado) - Universidade Federal do Rio de Janeiro, Rio de Janeiro, 2003.

FIGUEIREDO, Carlos Figueiredo Guimarães; OLIVEIRA, Márcia Santos Duarte. Português do Libolo, Angola, e português afro-indígena de Jurussaca, Brasil: cotejando os sistemas de pronominalização. Papia, Brasília, v. 23, n. 2, p. 105-185, 2013.

INVERNO, Liliana. Português vernáculo do Brasil e Português vernáculo de Angola: reestruturação parcial vs. mudança linguística. In: FERNÁNDEZ, Mauro; FERNÁNDEZFERREIRO, Manuel; VÁZQUEZ VEIGA, Nancy (Ed.). Los Criollos de base ibérica: ACBLPE. Madrid: Iberoamericana/Frankfurt am Main: Vervuert, 2004. p. 201-213.

LABOV, William. Principles of Linguistic Change: Internal Factors. London, New York: Basil Blackwell, 1994. v. 1.

LUCCHESI, Dante. As duas grandes vertentes da história sociolingüística do Brasil (1500-2000). DELTA. São Paulo. v. 17, n. 1, p. 97-132, 2001.
Língua e sociedade partidas: a polarização sociolinguística no Brasil. São Paulo: Contexto, 2015.

LUCCHESI, Dante; BAXTER, Alan; SILVA, Jorge Augusto Alves da. A concordância verbal In: LUCCHESI, Dante; BAXTER, Alan; RIBEIRO, Ilza (Org.). O Português Afro-Brasileiro. Salvador: EDUFBA, 2009. p. 331-371.

MAGALHÃES, Telma. $O$ sistema pronominal sujeito e objeto na aquisição do português europeu e do português brasileiro. 2006. 187fl. Tese (Doutorado em Linguística) Universidade de Campinas, 2006.

MARINS, Juliana Esposito. Ter, haver e existir: a representação do sujeito pronominal nas construções existenciais numa perspectiva diacrônica. 2013. 166 f. Tese (Doutorado em Letras Vernáculas) - Universidade Federal do Rio de Janeiro. Rio de Janeiro, 2013

MATTOS E SILVA, Rosa Virgínia; MACHADO FILHO, Américo Venâncio Lopes. Variação ter/haver. In: LOBO, Tânia; OLIVEIRA, Klebson (Org.). África à vista. Salvador: EDUFBA 2009. p. 338-351.

MATTOS E SILVA, Rosa Virgínia. A variação haver/ter. In (Org.). A carta de Caminha: testemunho linguístico de 1500. Salvador: EDUFBA, 1996. p. 181-193.

MINGAS, Amélia Arlete. Interferência do kimbundo no português falado em Luanda. Luanda: Caxinde, 2000

MIRA MATTEUS, Maria Helena et al. Gramática da Língua Portuguesa. 2. ed. Lisboa: Caminho, 1989

__. Gramática da Língua Portuguesa. 6.ed. Lisboa: Caminho, 2006.

OLIVEIRA, Márcia Santos Duarte et al. O português afro-indígena e a comunidade de Jurussaca. In: AVELAR, Juanito; ALVAREZ LOPES, Laura (Org.). Dinâmicas Afro-Latinas -Língua(s) e História(s). Berlin: Peter Lang, 2015. v. 1, p. 149-178.

PETTER, Margarida. Uma hipótese explicativa do contato entre o português e as línguas africanas. In: Papia, Brasília, v. 17, n. 1, p. 09-19, 2007.

RIBEIRO, Ilza. A formação dos tempos compostos: a evolução histórica das formas ter haver e ser. In: ROBERTS, Ian; KATO, Mary (Org.). Português brasileiro: uma viagem diacrônica. Campinas: UNICAMP, 1996. p. 343-386.

SAMPAIO, MARIA LÚCIA PINHEIRO. Estudo diacrónico dos verbos TER e HAVER, duas formas em concorrência. Assis: Nigro, 1978. 
SANKOFF, David; TAGLIAMONTE, Sali; SMITH, Eric. Goldvarb X: Computer program. Departament of Linguistics, University of Toronto, Canada. Disponível em: <http:// individual.ca/tagliamonte/goldvarb/GV_index.htm. 2005>. Acesso em: 16 out. 2011.

TARALLO, Fernando. Diagnosticando uma gramática brasileira: o português d'aquém r d'além mar ao final do século XIX. In: ROBERTS, Ian; KATO, Mary (Org.). Português brasileiro: uma viagem diacrônica. Campinas: Editora da UNICAMP, 1993. p. 69-105.

TEIXEIRA, Eliana Pitombo. O pronome você no português de Luanda. In: LIMAHERNANDES, Maria Célia et al. (Org.). A língua portuguesa no mundo: I Simpósio Mundial de Estudos de Língua Portuguesa. São Paulo: FFLCH-USP, 2008. p. 1-16.

Aspectos da pronominalização do português vernacular de Luanda: uma comparação com o português do Brasil. In: LOPES, Norma da Silva; BULHÕES, Lígia Pelon da Silva; CARVALHO, Cristina dos Santos. (Org.). Sociolinguística: estudo da variação, da mudança e da socio-história do português brasileiro. Feira de Santana: UEFS Editora, 2013. p. $145-167$.

TEIXEIRA, Eliana S. Pitombo. O pronome você no português de Luanda. In: LIMA Hernandes, Maria Célia et al. (Org.). A língua portuguesa no mundo. São Paulo: FFLCHUSP, 2008.

TEIXEIRA, Eliana S. Pitombo; ALMEIDA, Norma Lucia Fernandes de. A indeterminação do sujeito no português angolano: uma comparação com o português do Brasil. Papia, Brasília, v. 21, n. 1, p. 99-111, 2011.

VIEIRA, Silvia Rodrigues. Concordância verbal: variação em dialetos populares do norte fluminense. Dissertação (Mestrado em Língua Portuguesa). Universidade Federal do Rio de Janeiro. Rio de Janeiro, 1995.

VITÓRIO, Elyne Giselle de Santana Lima Aguiar. Aquisição e variação dos verbos ter e haver existenciais no PB. Veredas, UFJF (online), v. 14, n. 1, p. 53-63, 2010.

As construções existenciais com ter e haver: o que tem na fala e o que há na escrita. Domínios de Lingu@Gem, v. 7, n. 2, p. 71-89, 2013. 